\title{
A COMPARISON OF AEROSOL-LAYER AND CONVECTIVE BOUNDARY-LAYER STRUCTURE OVER A MOUNTAIN RANGE DURING STAAARTE 97
}

\author{
S. F. J. DE WEKKER ${ }^{1,2,3, \star}$, D. G. STEYN ${ }^{1}$ and S. NYEKI ${ }^{2,4}$ \\ ${ }^{1}$ The University of British Columbia, Canada; ${ }^{2}$ Paul Scherrer Institute, Villigen, Switzerland; \\ ${ }^{3}$ Pacific Northwest National Laboratory, P.O. Box 999, MSIN K9-30, Richland, WA 99352, \\ U.S.A.; ${ }^{4}$ University of Essex, Colchester, Essex U.K.
}

(Received in final form 29 December 2003)

\begin{abstract}
The temporal evolution and spatial structure of the aerosol layer (AL) height as observed with an airborne downlooking lidar over the Swiss Alps were investigated with a three-dimensional mesoscale numerical model and a particle dispersion model. Convective boundary-layer (CBL) heights were derived from the mesoscale model output, and the behaviour of surface-released particles was investigated with the particle dispersion model. While a previous investigation, using data from the same field study, equated the observed AL height with the CBL height, the results of the current investigation indicate that there is a considerable difference between $\mathrm{AL}$ and $\mathrm{CBL}$ heights caused by mixing and transport processes between the CBL and the free atmosphere. CBL heights show a more terrain-following behaviour and are lower than AL heights. We argue that processes causing the difference between AL and CBL heights are common over mountainous terrain and that the AL height is a length scale that needs to be considered in air pollution studies in mountainous terrain.
\end{abstract}

Keywords: Aerosol layer, Boundary-layer height, Convective boundary layer, Lidar, Mountainous terrain, Numerical modelling.

\section{Introduction}

While considerable past research has focused on convective boundary-layer (CBL) structure in valleys (Whiteman, 1990), CBL structure over mountain ridges and slopes has received relatively little attention. Holzworth (1964) and Raymond and Wilkening (1980) noted the frequent presence of a deep afternoon CBL over mountainous terrain in western North America, with CBL depths of up to $2-3 \mathrm{~km}$ over the mountain ridges. Potential temperature analyses in studies by Cramer and Lynott (1961) and Cramer (1972) show similar CBL depths in mountainous terrain. Braham and Draginis (1960) made aircraft observations over a mountain range and investigated the nature of thermals. Their cross-sections of potential temperature in the afternoon CBL reveal the presence of thermals over the highest peaks and

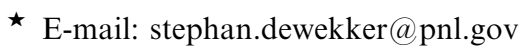

Boundary-Layer Meteorology 113: 249-271, 2004.

(C) 2004 Kluwer Academic Publishers. Printed in the Netherlands. 
ridges. Observations in hilly and mountainous terrain show that, while the CBL structure in the early morning is highly inhomogeneous, the afternoon CBL structure tends to be horizontally homogeneous (Lenschow et al., 1979; Fiedler, 1983). Dayan et al. (1988) found that orography was the major factor determining CBL height variability, rather than differences in synoptic conditions or land use. Radiosonde and aircraft data from a field study in the Black Forest region in Germany show a variety of behaviours, from a CBL that follows the underlying terrain to a CBL that seems unaffected by terrain irregularities (De Wekker et al., 1997; Kossmann et al., 1998).

Conventionally, CBL heights have been determined from vertical temperature profiles. However, the spatial density of vertical profile measurements is often not sufficient to study spatial CBL height behaviour in mountainous areas. Aircraft measurements offer one solution to this problem but suffer from the complication that boundary-layer structure can change significantly during the time that it takes to sample different parts of an experimental area. In recent years, the development of remote sensors such as sodar and lidar has provided the opportunity to study CBL heights at high temporal and spatial resolution. Particularly, downlooking airborne lidar aboard an aircraft has proven useful for the investigation of the spatial variability of CBL height (e.g., Kiemle et al., 1995). More accurately, the height of the aerosol layer (AL) is determined from lidar data, not the CBL height. Several studies over flat terrain have shown good correspondence between CBL and AL heights derived from temperature profiles and lidar, respectively (van Pul et al., 1994; Marsik et al., 1995). Others have found that CBL heights from lidar measurements are slightly higher (Coulter, 1979). Overall however, it has been assumed that AL and CBL heights are equal. This assumption has been supported by the fact that lidar backscatter images frequently show small-scale AL top structure that resembles the CBL top structure arising from the penetration of thermal eddies into an elevated inversion layer as found in laboratory studies (Deardorff et al., 1980) and large-eddy simulations (Sullivan et al., 1998).

Lidar data could be very useful for determining the spatial variability of the CBL height in mountainous terrain under conditions when sufficient aerosols are present. It is still unclear, however, whether AL and CBL heights are synonymous in mountainous terrain. Nyeki et al. (2000) used an aircraft with a downlooking lidar and aerosol instrumentation on one day in the Swiss Alps to conclude that the CBL height did not follow the underlying topography (assuming that the CBL height equated to the AL height). No observations of atmospheric temperature structure, however, were available to confirm this conclusion. In the current paper, we use a three-dimensional non-hydrostatic mesoscale numerical model and Lagrangian particle dispersion model to simulate the one day in Nyeki et al.'s (2000) dataset and to investigate if the assumption of equal $\mathrm{AL}$ and $\mathrm{CBL}$ heights can be justified 
over mountainous terrain. At the same time, we will attempt to explain the AL height behaviour over mountainous terrain from the combined use of a numerical model and observations.

\section{Data}

Under the European Union's 'scientific training and access to aircraft for atmospheric research throughout Europe' (STAAARTE) project, an airborne field study was conducted in an area of approximately $\times 0.5^{\circ}$ latitude $\times 0.5^{\circ}$ longitude around the Jungfraujoch high-alpine research station (JFJ, 46.55 $\mathrm{N}, 7.98^{\circ} \mathrm{E} ; 3454 \mathrm{~m}$ a.s.l.) in Switzerland, on 30 July 1997. On this day, a high-pressure ridge from southern France to Scandinavia determined the weather situation with cloudless skies over large parts of Europe. Synoptic winds in the investigation area were weak to moderate $\left(5-10 \mathrm{~m} \mathrm{~s}^{-1}\right.$ at $500 \mathrm{hPa}$ ) and from a north-westerly direction.

The JFJ (Figure 1) is located in the northern part of the Swiss Alps in the Bernese Oberland and is situated in a saddle between the Mönch (4099 m) and Jungfrau $(4158 \mathrm{~m})$ peaks. The Aletsch glacier, an important terrain feature south of the JFJ, is indicated in Figure 1.

A downlooking aerosol lidar (Nd-YAG laser, output wavelength $(\lambda)$ of $532 \mathrm{~nm}$ ) was flown on the German Aerospace Research Establishment (DLR) Falcon-20 jet aircraft (Kiemle et al., 1995) to obtain an aerosol structure dataset with high temporal and spatial resolution below $5 \mathrm{~km}$ a.s.l. The horizontal and vertical resolutions of the lidar measurements were approximately $100 \mathrm{~m}$ and $15 \mathrm{~m}$, respectively.

Lidar measurements were made with identical morning and afternoon flight patterns over the JFJ. Flight patterns consisted of transects oriented parallel and perpendicular to the north-east to south-west oriented regional mountain divide. A total of 35 flight legs were flown; 17 in the morning between 0628 and 0925 UTC, and 18 in the afternoon between 1247 and 1533 UTC, each leg lasting between 2 and $8 \mathrm{~min}$. The daylight period at the JFJ on 30 July 1997 was from 0407 to 1902 UTC so that the first flights took place more than $2 \mathrm{~h}$ after local sunrise. The north-west to south-east transect makes a sharp topographical transition from the pre-alpine foothills in the Emmental region (up to $2000 \mathrm{~m}$ ) through the JFJ and the surrounding massif (3000-4000 m), and down over the Aletsch glacier towards the Rhone Valley. To the north of the JFJ, the topography falls $3 \mathrm{~km}$ over a distance of only $15 \mathrm{~km}$ into a valley that issues onto the Swiss plateau. Lidar backscatter ratio cross-sections of all 35 flight tracks are shown in De Wekker (2002). The dashed line in Figure 1 depicts the approximate location of the flight tracks that are discussed in this paper. 


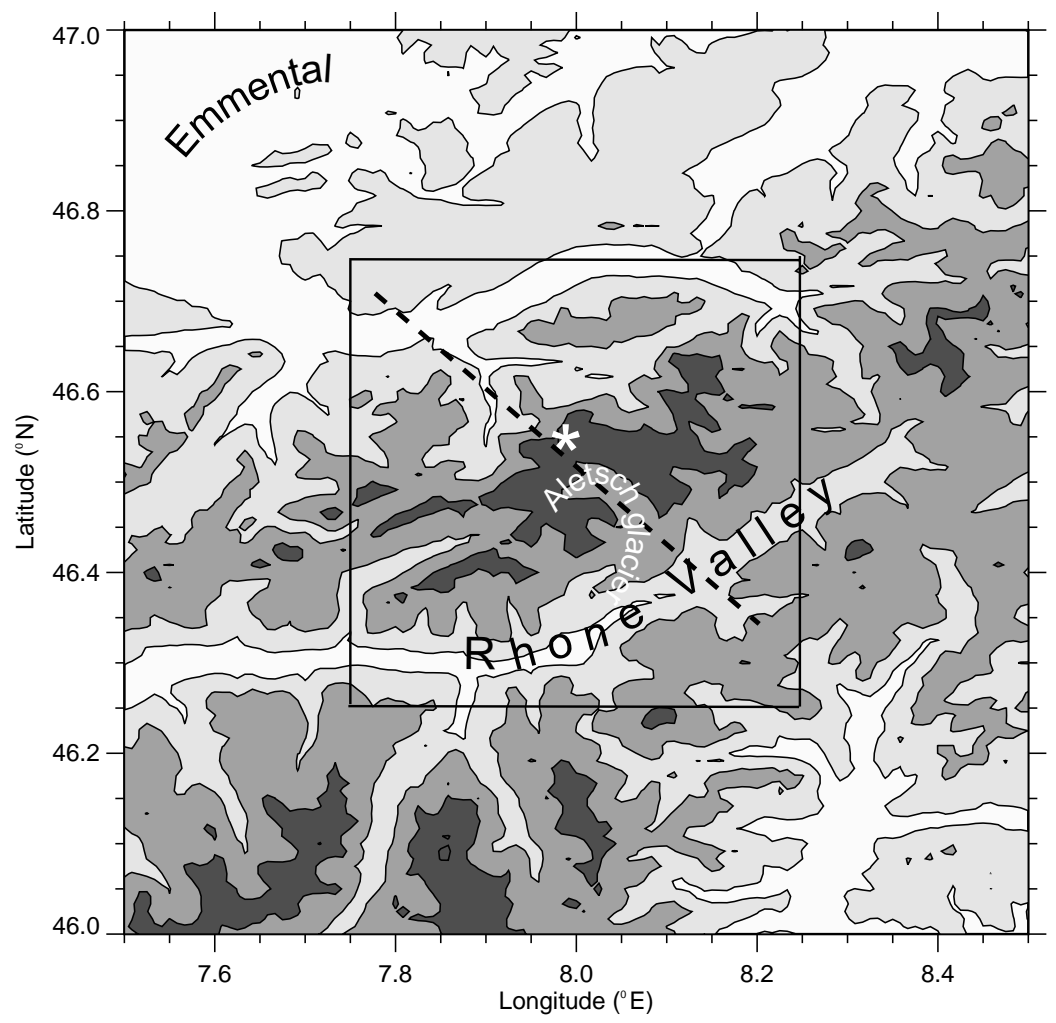

Figure 1. Topographic map of the experimental area. Contour lines are drawn every $1000 \mathrm{~m}$, the darkest shade representing terrain over $3000 \mathrm{~m}$ a.s.1. The Jungfraujoch station is depicted by the white asterisk. The approximate location of flight tracks perpendicular to the mountain divide is depicted by the dashed line. The inner square represents the innermost grid for the mesoscale model run described in Section 4.

\section{Observations of the Aerosol-Layer Height}

The observed spatial and temporal evolution of AL height on 30 July 1997 is shown in Figure 2 by a series of lidar cross-sections taken along a flight track (Figure 1) perpendicular to the mountain divide. Shown in the lidar crosssections are the topography (in white) and the backscatter ratio $B=\left[B_{\mathrm{a}}+B_{\mathrm{m}}\right] /\left[B_{\mathrm{m}}\right]$, where $B_{\mathrm{a}}$ is aerosol scattering and $B_{\mathrm{m}}$ is molecular scattering. $B$ is affected by aerosol number, size distribution, composition, lidar wavelength $\lambda$, and relative humidity, and is predominantly influenced by accumulation mode aerosols having diameters between 0.1 and $1.0 \mu \mathrm{m}$ (Schwiesow, 1984). On some occasions, $B$ shows significant variability within the AL, and may be due to increased aerosol concentrations from natural or anthropogenic activity as well as to aerosol growth at relative humidities above $85 \%$ (Hänel, 1976). 
The evolving AL was observed to grow in height over time while generally maintaining a nearly uniform height despite significantly varying topography. Winds were north-westerly at the AL height during the entire period of observations, and the AL height was up to about $500 \mathrm{~m}$ lower to the northwest compared to the south-east of the mountain divide.

In the morning hours, the JFJ was above the top of the aerosol layer, aerosol measurements taken at JFJ (sub-section 5.2) confirming this (also see Nyeki et al., 2000). Between 0702 and 0913 UTC, the aerosol layer grew only slightly, most of its growth of about $1 \mathrm{~km}$ occurring between 0913 and 1317 UTC when the maximum AL height reached slightly above $4000 \mathrm{~m}$ a.s.1. (Figure 2c). Between 1317 and 1520 UTC, the additional AL growth was small.

The AL top here is relatively smooth compared to the AL top over flat terrain (e.g., Kiemle et al., 1995). Frequently, lidar cross-sections over flat terrain show irregularities that indicate the presence of vigorous thermal eddies stirring air within the CBL. This is not evident in the lidar crosssections from STAAARTE '97.

The AL height generally does not follow the individual ridges and valleys in the underlying terrain on a scale of a few kilometres but there is a tendency to follow the topography on a scale of a few tens of kilometres. The examples shown here are representative of all other lidar cross-sections (De Wekker, 2002).

For our analyses, the AL height from the cross-sections was determined from vertical profiles of aerosol backscatter using the semi-objective method illustrated in Figure 3. This method is applied in the usual case where backscatter ratios decrease with height. The approach is to determine layers in the lower and upper atmosphere where backscatter ratios are fairly constant with height (vertical solid lines in Figure 3); the mean of the backscatter ratios in the lower and upper layer (vertical dashed line in Figure 3) was then taken as the threshold value. The AL height is defined as the height where this threshold value is first exceeded, commencing from the top of the backscatter profile. Erroneous backscatter ratios near the surface are not considered in determining the backscatter ratio for the lowest layer. With this method, the AL height is relatively insensitive to the subjective values of A and B (Figure 3) that define the upper limit of the lower layer and the lower limit of the upper layer, respectively. After application of the method, the AL heights are inspected to detect any failures of the algorithm. Values using the semi-objective method are shown by the black line in Figure $2 \mathrm{~d}$.

A second, subjective method was also used for comparison with the semiobjective method, in which a visually determined AL top was selected. These heights were somewhat larger than for the semi-objective method. Differences between the two methods, however, were small with maximum differences of about $200 \mathrm{~m}$. 

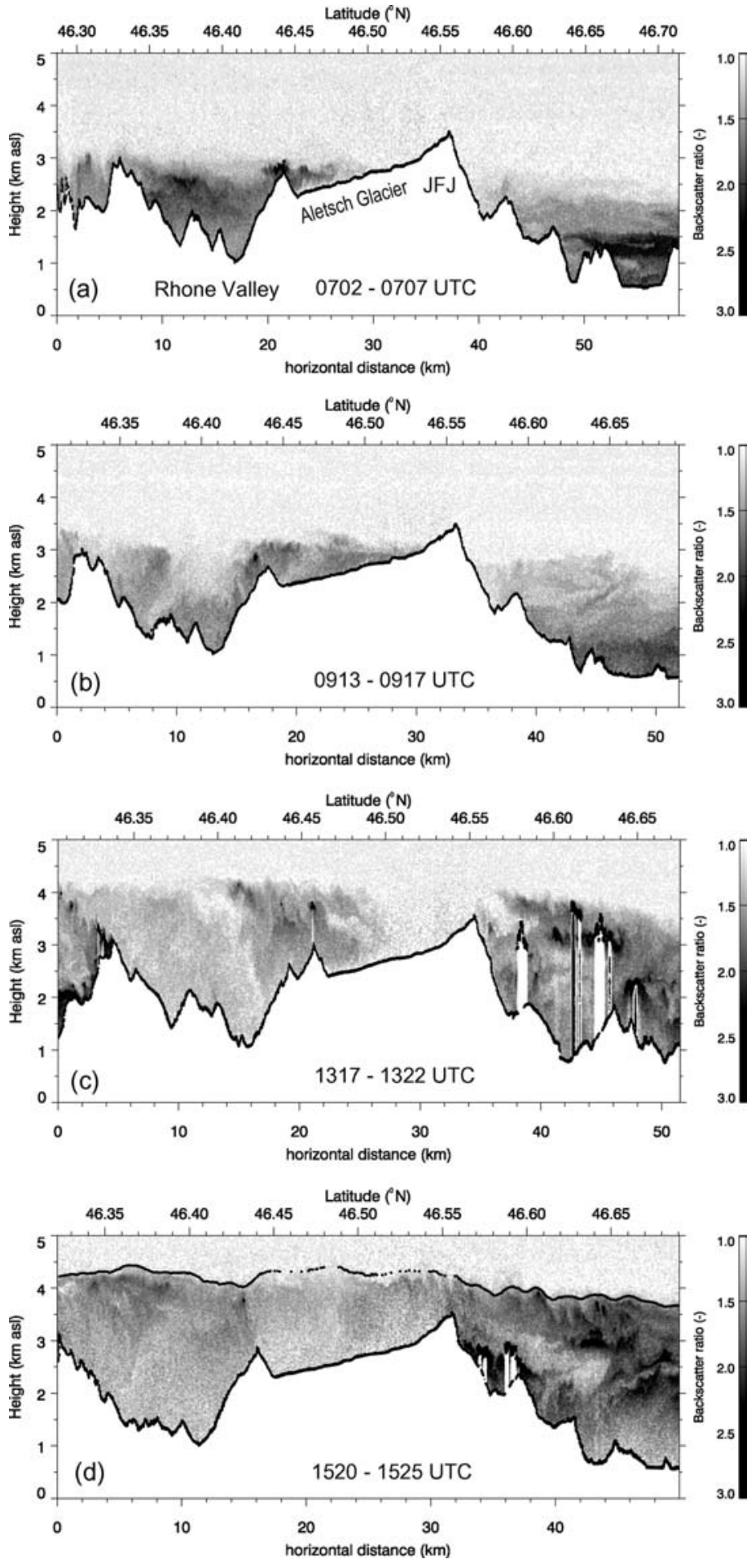


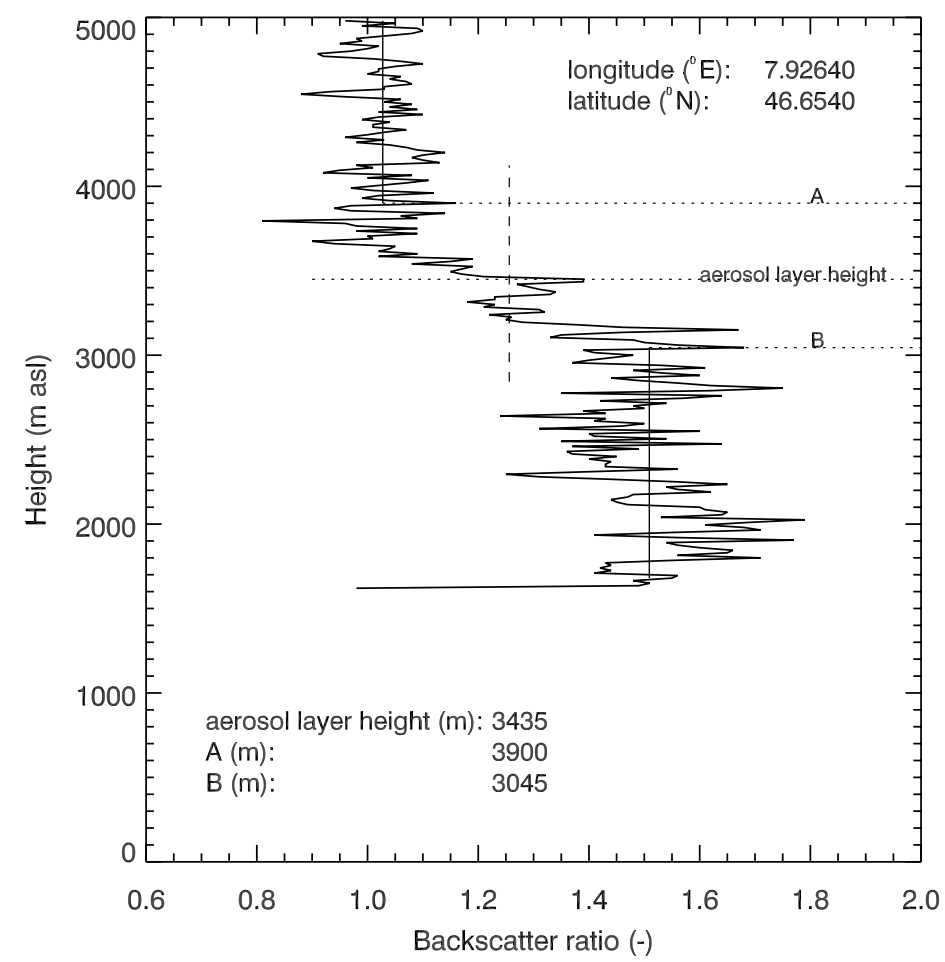

Figure 3. Illustration of the AL height determination with the semi-objective method. See text for details.

The temporal evolution of the leg-averaged AL height is depicted in Figure 4 for 13 out of the 17 morning flight tracks, and 15 out of the 18 afternoon flight tracks; the other flight tracks were not well-suited for determination of the AL height. AL heights during the morning flight are between 2 and $3 \mathrm{~km}$ a.s.l., and in the afternoon they are between 3 and somewhat over $4 \mathrm{~km}$ a.s.l. The few data points with relatively low values early in the morning and early in the afternoon correspond to flights over the terrain north-west of the mountain divide where terrain height is relatively

Figure 2. Cross-sections of lidar backscatter ratio on the flight track shown in Figure 1 for flights starting at 0702 (a), 0913 (b), 1317 (c), and 1520 UTC (d). The colour scale is proportional to lidar backscatter ratio, with white indicating the underlying topography. The Rhone Valley, Aletsch Glacier, and Jungfraujoch station (JFJ) are indicated in (a). Slight differences in the underlying topography in (a)-(d) were caused by minor variations in the flight path. As an example of the results from the semi-objective method of determining AL height, see the black line in (d). The white vertical lines on some of the cross-sections indicate the presence of clouds. 


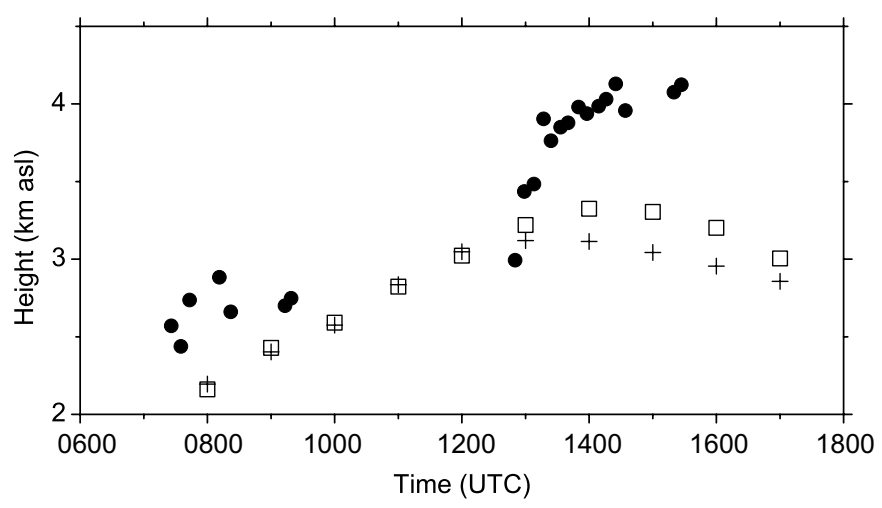

Figure 4. Observed leg-averaged AL heights (filled circles) and CBL heights (pluses and squares) from model output. Squares are CBL heights from model output averaged over a 15$\mathrm{km}$ wide band perpendicular to the mountain divide. Plusses are CBL heights from model output averaged over a $15-\mathrm{km}$ wide band parallel to the mountain divide. CBL heights from model output are discussed in sub-Section 6.2.

low. Unfortunately, no measurement was made between 0900 and 1300 UTC, the time of most rapid AL growth.

\section{Model Set-Up and Evaluation}

The mesoscale numerical model used to investigate the processes underlying the observed AL heights is the regional atmospheric modeling system (RAMS), version 4.3. RAMS solves a set of dynamic equations in their nonhydrostatic, compressible form, a thermodynamic equation, and a set of cloud microphysical equations. It predicts the three velocity components, potential temperature, mixing ratio, and subgrid-scale turbulence kinetic energy (TKE) in a terrain-following coordinate system. The ability of RAMS to model complex terrain phenomena has been demonstrated in previous studies (e.g., Fast and Zhong, 1998). Details of the model can be found in Cotton et al. (2003).

Convective parameterization was not required in the simulations because the horizontal resolution was fine enough for the model to develop its own convective circulations. Because cloud cover was minimal, as indicated by shortwave radiation measurements and satellite images (De Wekker, 2002), water vapour was treated as a passive scalar.

Terrain heights and land use types were obtained from the United States Geological Survey (USGS) 30 arc-second dataset. Glacier boundaries correspond well with the USGS data, with land use below $2500 \mathrm{~m}$ consisting largely of urban, agricultural and forested areas. Sandy loam was used as the 
TABLE I

Characteristics of the four gids used in STAAARTE '97 modeling case study.

\begin{tabular}{lllllll}
\hline GRID & NX & NY & $\begin{array}{l}\text { Grid spacing } \\
(\mathrm{km})\end{array}$ & $\begin{array}{l}W-E \\
\text { Size }(\mathrm{km})\end{array}$ & $\begin{array}{l}N-S \\
\text { Size }(\mathrm{km})\end{array}$ & $\Delta T(\mathrm{~s})$ \\
\hline 1 & 50 & 50 & 27 & 1350 & 1350 & 60 \\
2 & 50 & 50 & 9 & 450 & 450 & 30 \\
3 & 62 & 62 & 3 & 186 & 186 & 15 \\
4 & 41 & 59 & 1 & 41 & 59 & 7.5 \\
\hline
\end{tabular}

$\mathrm{NX}$ and NY are the number of grid points in the west-east, and north-south direction, respectively. $\Delta t$ is the model time step in seconds.

soil type over the entire domain, with the volumetric soil moisture content set to 0.28 .

The three-dimensional simulations were made over a $1350 \times 1350 \mathrm{~km}^{2}$ domain centered over the JFJ, with the domain consisting of four nested grids; information on grid characteristics is given in Table I. The outermost grid covers central Europe including the Alps, while the innermost grid is shown in more detail in Figure 1 (inner rectangle) and Figure 7. The four grids have horizontal grid spacings of $27,9,3$, and $1 \mathrm{~km}$. The choice of the horizontal grid spacing of $1 \mathrm{~km}$ was based upon consideration of the dominant horizontal scales of topography in the innermost grid. A wavelet analysis indicated that these scales were on the order of $5 \mathrm{~km}$ or larger (De Wekker, 2002). Given that features of $2 \Delta x$ to $4 \Delta x$ are resolved in the model (Pielke, 2002), where $\Delta x$ is the horizontal grid spacing, a $\Delta x$ of $1 \mathrm{~km}$ is an appropriate choice.

All four grids have 53 vertical levels, with a grid spacing increasing from 50 near the surface to $160 \mathrm{~m}$ at $2000 \mathrm{~m}$ a.g.l. to $1000 \mathrm{~m}$ near the model top at about $16 \mathrm{~km}$; levels up to $10 \mathrm{~km}$ are indicated in Figure 5. Due to a staggered coordinate system, the lowest grid point is located about $25 \mathrm{~m}$ above ground level.

The simulations cover $36 \mathrm{~h}$, from 1200 UTC on 29 July to 0000 UTC on 30 July 1997. The five outermost lateral boundary points on the periphery of the largest domain were nudged toward NCEP objective analysis fields and radiosonde data to allow changes in large-scale conditions to influence the model simulations.

Model simulations were compared with temperature, humidity, and wind observations from aircraft and selected radiosonde stations around the investigation area. The Payerne, Switzerland $\left(46.82^{\circ} \mathrm{N}, 6.95^{\circ} \mathrm{E}, 490 \mathrm{~m}\right)$ and Milan, Italy $\left(45.43^{\circ} \mathrm{N}, 9.28^{\circ} \mathrm{E}, 107 \mathrm{~m}\right)$ radiosonde stations were chosen since 

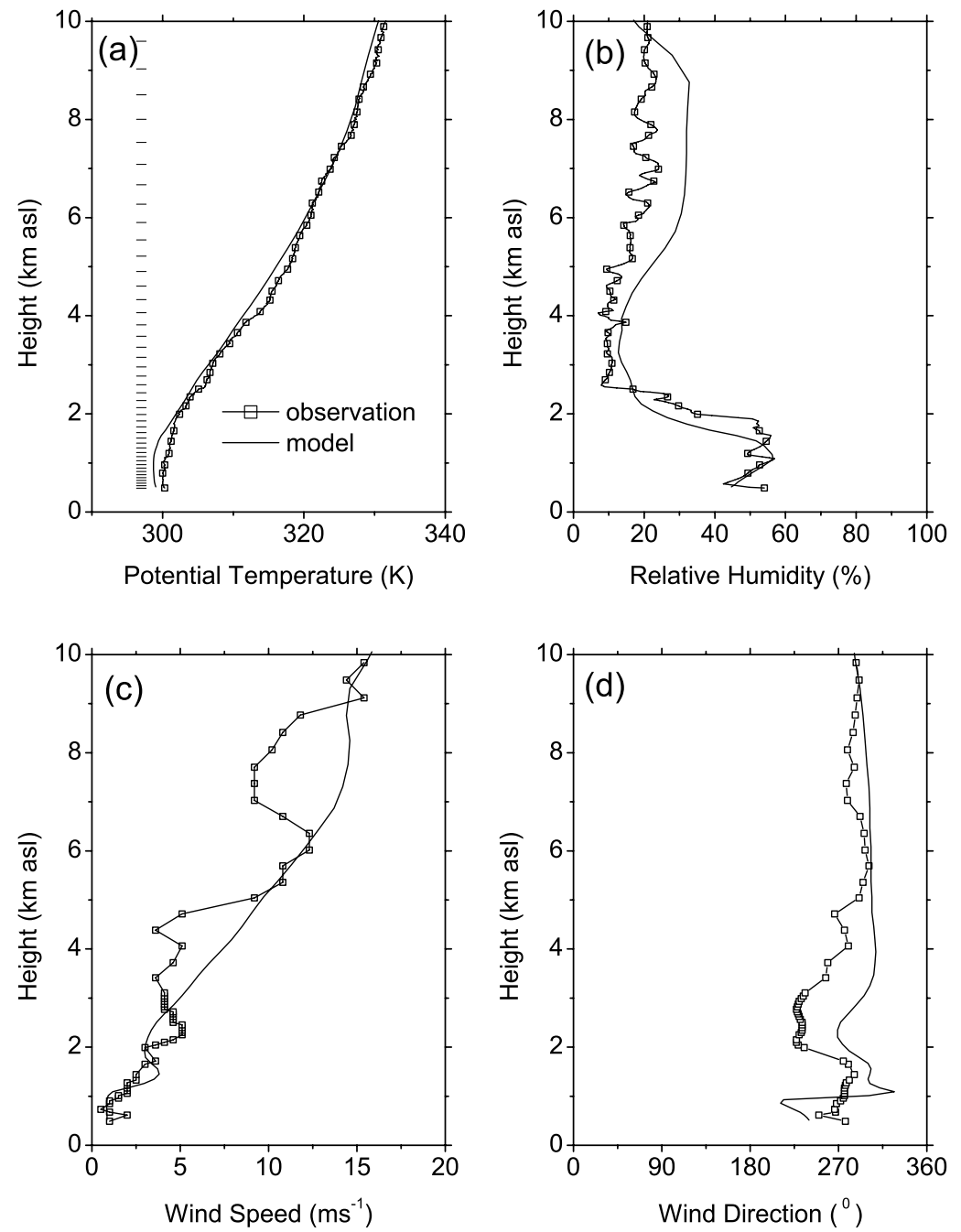

Figure 5. Observed (squares) and modelled (solid lines) vertical profiles of potential temperature (a), relative humidity (b), wind speed (c), and wind direction (d) for Payerne at 1200 UTC 30 July 1997. The vertical grid spacing in the model is indicated in (a) by the small horizontal lines.

they are located close to the STAAARTE investigation area. With northwesterly synoptic winds, Payerne is upwind, and Milan downwind, of the Alps. Unfortunately, no soundings were taken in the investigation area except for aircraft descent/ascent profiles over the JFJ at around 0900 and 1500 UTC. Comparisons between observations and simulations are shown in Figure 5 for Payerne and in Figure 6 for Milan, and the aircraft soundings above the JFJ. The model is not able to capture the details of vertical structure seen in the observations but there is close correspondence with the 

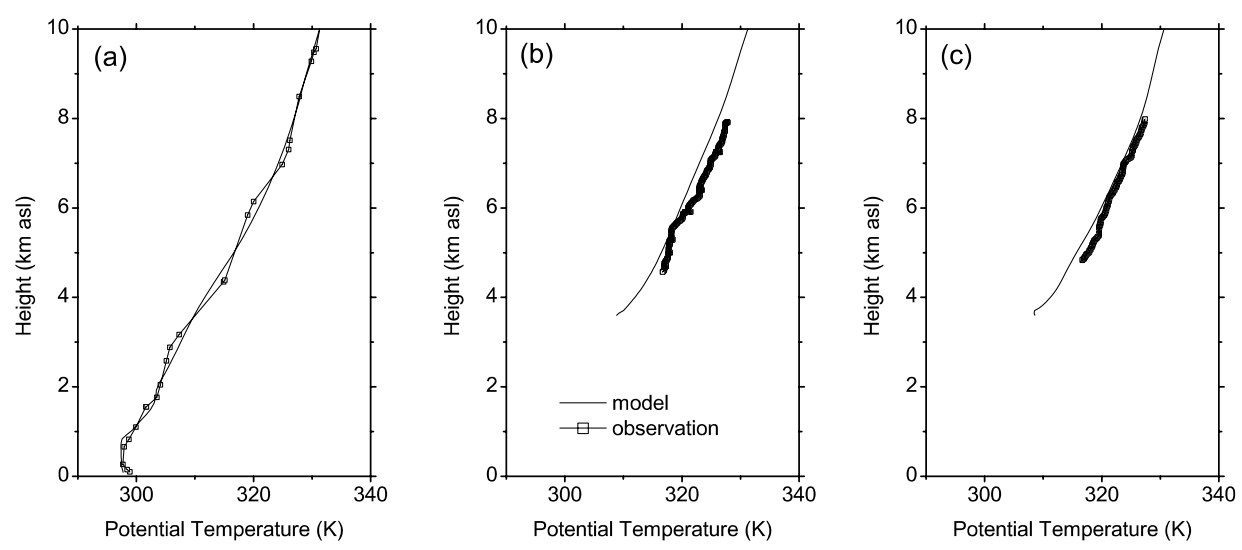

Figure 6. Observed (squares) and modelled (solid lines) vertical profiles of potential temperature for Milan at 1200 UTC (a), above the Jungfraujoch at 0900 UTC (b) and above the Jungfraujoch at 1500 UTC (c) on 30 July 1997.

overall vertical structure. This encourages a further investigation of CBL morphology with the mesoscale numerical model.

\section{Lagrangian Particle Dispersion Model Simulation and Comparison with Observations}

The Hybrid particle and concentration transport (HYPACT) Lagrangian particle dispersion model (LPDM) is used here to gain a better understanding of the observed aerosol structure over mountainous terrain. Recent applications of HYPACT, as described by Walko et al. (2001) can be found in Lyons et al. (1994) and Lagouvardos et al. (1996).

The main objective of the LPDM simulation was to examine if the AL height observed from the lidar can be simulated by releasing particles at the surface. For this purpose, HYPACT was run using the RAMS model output validated in the previous section. Particles were continuously emitted at $2 \mathrm{~m}$ above the ground at a rate of 2000 particles per hour starting at 0400 UTC in two valley regions north-west and south-east of the mountain range (solid rectangles in Figure 7), simulating the main sources of aerosols in the area. Since the surface elevation is well below $2000 \mathrm{~m}$ in these regions, particles that are found above this height in the simulations are carried there by CBL growth or other processes. Particles undergo the same turbulent mixing as the surrounding fluid, and gravitational forces on mean particle motion are neglected. Results of the LPDM simulation and comparison with observations will be presented next. 


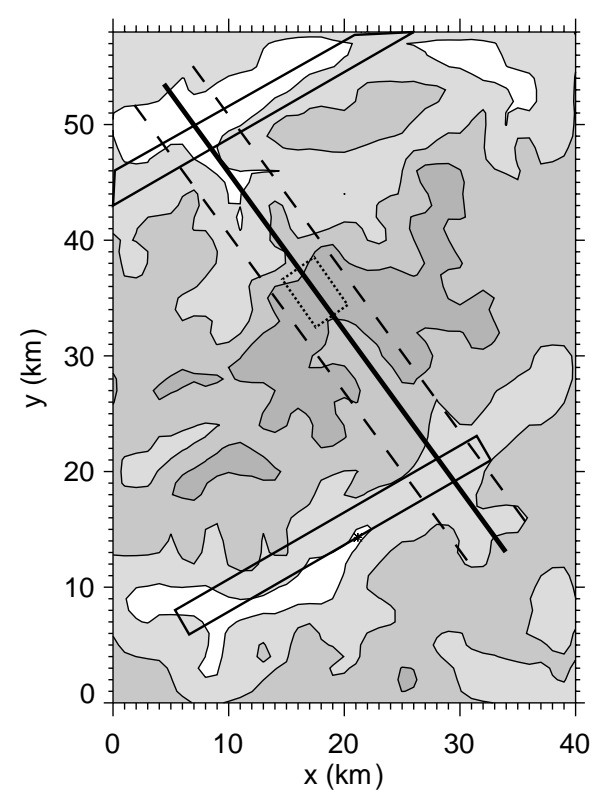

Figure 7. Topographic map of the innermost RAMS grid. Contour lines are drawn every $1000 \mathrm{~m}$, the darkest shade representing terrain over $3000 \mathrm{~m}$ a.s.l. The solid rectangles indicate the release areas of the particles; the solid line indicates the location of the cross-section in Figure 8 . For the meaning of the dashed lines and the dotted rectangle, see the text.

\subsection{SPATIAL DistRIBUTION OF PARTICLES}

If the simulated spatial distribution of particles is comparable to the aerosol backscatter cross-sections in Figure 2, the underlying reasons for this spatial distribution can be investigated further. The distribution of the particles at 0900, 1200, and 1500 UTC in a 6-km-wide band centered on the cross-section perpendicular to the mountain divide (dashed lines in Figure 7), is shown in Figure 8 . The width of the band was chosen so that enough particles could be captured while keeping the variability of the terrain across the band to a minimum. The cross-section in Figure 8 corresponds approximately to the cross-sections shown in Figure 2, allowing direct comparisons of the LPDM simulations with AL height determinations from the semi-objective method, which are also shown in Figure 8.

By 0900 UTC, i.e., $5 \mathrm{~h}$ after sunrise, a significant number of particles had already attained a height exceeding $3000 \mathrm{~m}$ south-east of the mountain divide and about $500 \mathrm{~m}$ lower north-west of the mountain divide. By 1200 UTC, the particle-filled layer south-east of the mountain divide exceeds $4000 \mathrm{~m}$ and the height difference across the mountain divide has increased to about $1000 \mathrm{~m}$. Between 1200 and 1500 UTC, the differences are minor. Sensitivity tests 

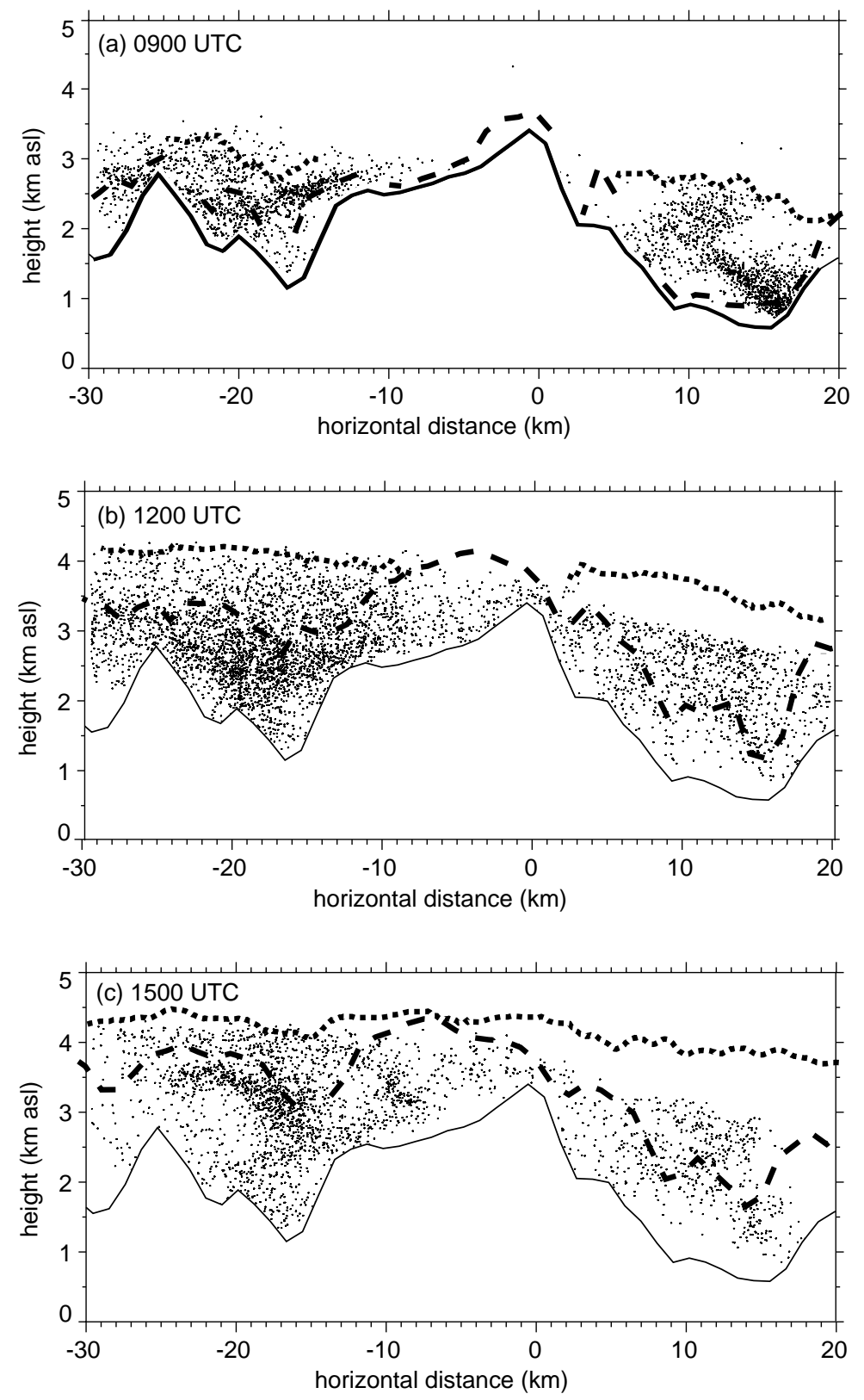

Figure 8. Cross-section of the particle distribution at 0900 UTC (a), 1200 UTC (b), and 1500 UTC (c) in a 6-km-wide band perpendicular to the mountain divide. The dotted lines in (a), (b), and (c) are observations of AL heights at 0913, 1317, and 1520 UTC from Figure 2. The dashed lines are CBL heights as determined from the model by the $R i$-method at 0900, 1200, and 1500 UTC. 
showed that the particle layer height was insensitive to the location of the source regions. Also, a simulation in which particles were released at homogeneously distributed surface locations everywhere in the domain resulted in a similar behaviour. The agreement between the simulated particle layer height and the observed AL height is very good south-east of the mountain divide, but the particle layer height is several hundred metres below the observed AL height north-west of the mountain divide.

Major surface flow patterns in the afternoon were constructed from the movement of the particles in the area by De Wekker (2002), where it was shown that the surface flow field is mainly dominated by the channeling of upvalley flows. Particles cross the mountain divide via upslope and upvalley flows through the passes on either side of the mountain divide. Superimposed on the thermally-driven flows is a synoptic north-westerly flow so that there is a general tendency for the particles to move towards the south-east. All these flows are responsible for the transport of particles to the top of the particle layer as was shown by the inspection of particle trajectories (De Wekker, 2002) and by observations of aerosols at JFJ for which the origin can be tracked (Lugauer, 1998).

Thus, the surface flow pattern establishes a mean upward motion in the valleys and slopes on both sides of the mountain divide that carries particles aloft. Particles in the simulation reach a height of $3 \mathrm{~km}$ as early as $0900 \mathrm{UTC}$, showing that the venting process is quite efficient in the morning hours. Observations at this time also show significant backscatter ratios at that height (see also Figure 2b). Thus, aerosols may have been transported there by thermally driven flows in the first few hours after sunrise and are not necessarily the remnant of a residual layer, as was suggested by Nyeki et al. (2000).

\subsection{DiURNAL VARIATION OF PARTICLES}

For synoptic winds from the west and north-west under anticyclonic weather conditions that are similar to the situation during this case study, the diurnal variation of average aerosol surface area per volume at the JFJ was investigated by Lugauer (1998) and is shown in Figure 9. The aerosol surface area starts to increase around 1000 UTC, reaches a peak in the late afternoon, and then gradually decreases. Recall from Figure 2 that the AL height had not reached JFJ by 0900; the measured aerosol surface areas support this conclusion. The line connected by diamonds shows the simulated diurnal variation of the number of particles arriving in the box of around $20 \mathrm{~km}^{2}$ centred on JFJ (dotted rectangle in Figure 7). The size of the box was chosen to capture a significant number of particles in an area close 


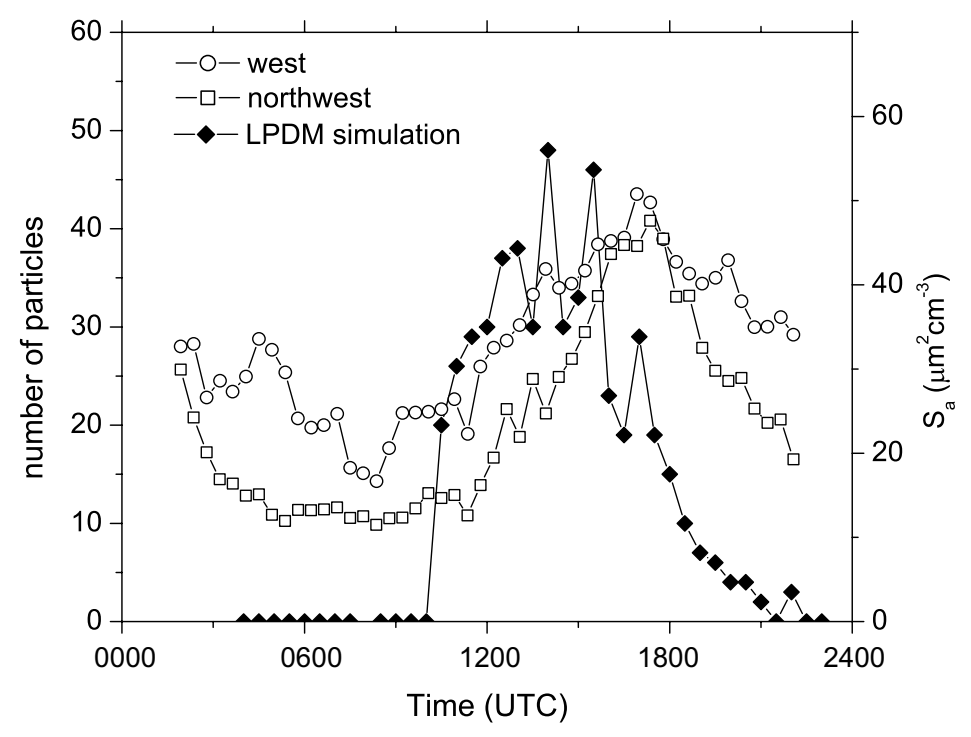

Figure 9. Diurnal variation of aerosol surface area per unit volume $S_{\mathrm{a}}$ (right axis) at the Jungfraujoch for $500 \mathrm{hPa}$ synoptic flows from the west (circles) and north-west (squares), averaged over the 7-year period 1991-1997 (Lugauer, 1998). The diamonds depict the diurnal range of particle numbers (left axis) arriving inside a box around JFJ from the LPDM simulation.

enough to the JFJ to be representative of aerosols sampled there. The timing of the increase corresponds well with the observations but the peak occurs somewhat earlier. Given the relatively small number of particles and the fact that local conditions at JFJ might have a considerable impact on the measurement of aerosol surface area (Lugauer, 1998), the agreement is reasonably good.

The good correspondence between the LPDM results and aerosol observations is encouraging and provides confidence in the simulation of the CBL structure by the mesoscale model. The CBL structure will now be investigated further by examining CBL heights from model simulations.

\section{CBL Heights from Model Simulations}

\subsection{CBL HEIGHT DETERMINATION METHOD}

CBL heights were determined using the Ri-method of Vogelezang and Holtslag (1996). $R i$ is calculated as

$$
R i=\frac{\left(g / \theta_{\mathrm{vs}}\right)\left(\theta_{\mathrm{vh}}-\theta_{\mathrm{vs}}^{\prime}\right)\left(h-z_{\mathrm{s}}\right)}{\left(u_{\mathrm{h}}-u_{\mathrm{s}}\right)^{2}+\left(v_{\mathrm{h}}-v_{\mathrm{s}}\right)^{2}+100 u_{*}^{2}},
$$


where $g$ is the acceleration due to gravity, $\theta_{\mathrm{vh}}, u_{\mathrm{h}}$, and $v_{\mathrm{h}}$ are the virtual potential temperature and the wind speed components at the boundary-layer height $h$ (a.s.l.), $\theta_{\mathrm{vs}}, u_{\mathrm{s}}$, and $v_{\mathrm{s}}$ are the virtual potential temperature and the wind speed components at the first model level (approximately $25 \mathrm{~m}$ ), $z_{\mathrm{s}}$ equals the height of the first model level (above a.s.1.), $u_{*}$ is the friction velocity at the surface, and $\theta_{\mathrm{vs}}^{\prime}=\theta_{\mathrm{vs}}+\Delta \theta$ where $\Delta \theta$ is a temperature excess (Troen and Mahrt, 1986), and which can be regarded as a measure of the strength of convective thermals (Vogelezang and Holtslag, 1996). Typical modelled temperature excesses were between 0.1 and $0.7 \mathrm{~K}$. $R i$ is calculated at each model level starting from the surface, and the CBL height is derived by linear interpolation between the level where $R i$ becomes larger than 0.25 , and the level below. The $R i$-method has been applied extensively to model simulations and observations and has been shown to perform well under a range of conditions (Vogelezang and Holtslag, 1996; Seibert et al., 2000).

De Wekker (2002) also used a method in which a cut-off value of the turbulence kinetic energy (TKE) is taken to determine the CBL height. These CBL heights corresponded well with CBL heights determined using the $R i$ method although applying the TKE method occasionally resulted in dubious values (De Wekker, 2002). In the following sections, we will only use CBL heights determined using the $R i$-method.

\subsection{COMPARISON OF THE CBL HeIGHT AND THE PARTICLE/AEROSOL LAYER HEIGHT}

Beginning as early as 0900 UTC, a significant number of particles reach as high as $1-2 \mathrm{~km}$ above the CBL in the valley regions. At this time CBL heights could not be determined at some locations where surface sensible heat fluxes were negative due to shading. As the CBL grows, the difference between CBL and particle-layer heights becomes smaller. Especially between 1200 and 1500 UTC, the CBL grows faster than the particle layer, while the maximum in both CBL and particle heights is achieved between 1400 and 1500 UTC. After this time, CBL and particle layer heights gradually decrease as convective processes become weaker and subsidence begins to dominate. Inspection of the wind field in the cross-section (not shown) indicates that near the Aletsch glacier there is a region where upvalley/upslope flows converge with the north-westerly synoptic flows. The associated rising motions establish a CBL height that is relatively deep in that area.

A comparison of observed AL heights and modelled CBL heights during the entire day is presented in Figure 4. Each black circle in Figure 4 represents the average of all observed heights along a single flight track, as discussed in Section 3. CBL heights were, as before, determined from RAMS output with the $R i$-method for each hour from 0800 to 1700 UTC. The 
squares and plusses symbols in Figure 4 represent averages that are representative of a flight track perpendicular and parallel to the mountain divide, respectively, so that a direct comparison with observed AL heights can be made. CBL heights were averaged over all the grid points within a $15-\mathrm{km}$ wide band centered around a line (representing the flight track) perpendicular and parallel to the mountain divide. CBL heights perpendicular to the mountain divide are up to about $200 \mathrm{~m}$ greater than CBL heights parallel to the mountain divide, particularly in the afternoon. This is caused by a greater average elevation of the topography along a section perpendicular to the mountain divide. These differences in CBL height, however, are small in comparison to the differences between CBL and AL heights. Overall, AL heights are significantly larger than CBL heights, with differences from a few hundred metres to one kilometre.

\section{Discussion}

To explain the observed aerosol structure in the afternoon, we present a conceptual diagram (Figure 10) that shows the relationship between AL and CBL heights and suggests several mechanisms that account for the differences. The various mechanisms are explained below. The wavy solid line depicts the lidar derived AL height, which is comparable to the height of the particle layer found from the LPDM simulation. The dashed line depicts the CBL height that was found from model output with the $R i$-method. AL heights, which are somewhat higher in the higher-elevation southern part of the mountain range and thus follow the large-scale topography to some

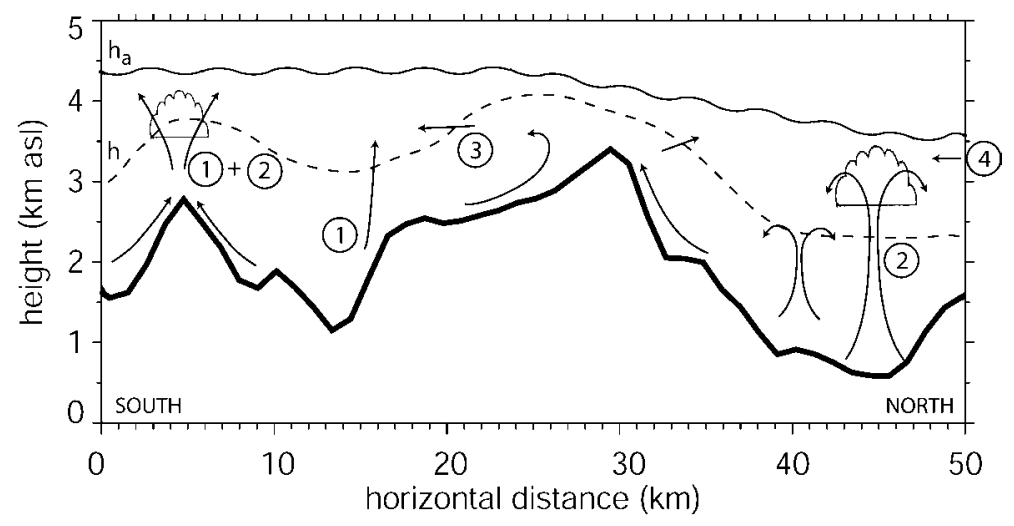

Figure 10. Conceptual diagram of the situation on the afternoon of 30 July 1997. The curve labelled $\mathrm{h}$ is the CBL height and the curve labelled $h_{\mathrm{a}}$ is the AL height. The depicted mechanisms are (1) mountain venting, (2) cloud venting, (3) advective venting, and (4) advection of aerosols from airmasses elsewhere. 
extent, reach a maximum altitude of about $4 \mathrm{~km}$ in the afternoon. CBL heights are considerably lower than AL heights, show more spatial variability, and tend to follow the terrain more than AL heights, although the extent to which the CBL height follows the terrain decreases during the day (De Wekker, 2002). Average CBL heights, like the AL heights, are lower in the lower-elevation northern part of the mountain range.

An additional simulation was performed in which the topography was removed and particles were released at exactly the same location as for the simulation with topography. The results showed that so few particles are seen above the CBL height that one could use the maximum height of the particles to determine the CBL height. This finding implies that AL and CBL heights can be equated over flat terrain, as is frequently done. Obviously, mountainous terrain exerts a profound influence on aerosol distribution in the atmosphere; mixing and transport processes in the investigation area are enhanced compared to those over flat and horizontally homogeneous terrain and the equality of AL and CBL heights ceases.

One of the mechanisms for the vertical transport of aerosols above mountain ranges relates to transport by slope flows (Fast and Zhong, 1998; Fiedler et al., 2000) The slope flow mechanism is enhanced when slope flows converge above mountain crests, a process that has been called the "chimney effect' (Lu and Turco, 1994), or when there is an additional sea-breeze flow in coastal terrain (McKendry et al., 1997). The vertical transport mechanisms directly associated with the presence of mountains are collectively referred to as mountain venting (mechanism 1 in Figure 10).

A second mechanism that is not necessarily related to topography but can also be important in transporting aerosol aloft occurs when thermals reach the lifting condensation level, so-called cloud venting (Ching et al., 1988, mechanism 2 in Figure 10). Cloud venting may be one of the possible mechanisms that transports aerosols above the CBL height. The mechanism is facilitated by the more vigorous thermals that are known to be present over mountainous terrain (e.g., WMO, 1993). In the model simulations described herein, cloud venting was not simulated. De Wekker (2002) performed a supplementary simulation in which the cloud parameterization was included, but relative humidities stayed well below $100 \%$ and clouds did not develop. Satellite images and solar radiation measurements also show that cloud cover was not significant. Thus, we conclude that cloud venting did not play a major role in this case study.

Another mechanism that can become important over mountainous terrain relates to advective venting (mechanism 3 in Figure 10), which occurs if a wind vector crosses an inhomogeneous CBL top (Kossmann et al., 1999). Mountain venting and advective venting have been investigated mainly in relation to elevated pollutant layers (McKendry and Lundgren, 2000). 
Interestingly, elevated layers did not appear in either the observations or model simulations.

The LPDM simulation suggests that a combination of mountain and advective venting processes (in addition to CBL growth) can explain to a large extent the observed aerosol structure. Particles that were released around sunrise were found at maximum heights comparable to the AL height. Aerosol advection from elsewhere (mechanism 4 in Figure 10) and cloud venting were not simulated, and are not necessarily needed to explain general AL height behaviour. One possible explanation for the lower particle height in the northern part of the investigation area in the simulations compared to the AL from the lidar data may be the non-existence of particle sources upwind of the model domain.

The LPDM simulation also suggests that the AL grows more rapidly and attains its maximum height earlier than the CBL does. The AL height is rather constant during the afternoon while the CBL height continues to increase somewhat, although at a smaller rate than in the morning. Therefore, the differences between AL and CBL heights become smaller during the afternoon. In late afternoon, the difference is smallest in the southern half of the investigation area but still amounts to a few hundred metres, as indicated in Figure 10.

Inspection of simulated temperature profiles in the area shows that three stability regimes can be identified: an unstable layer near the surface (the CBL), a layer between the CBL and AL heights that is slightly stable, and a more stable layer above the AL height that is identical to the free atmosphere. The turbulent character of the CBL in comparison with the nonturbulent character of the layer between the CBL and AL heights is obvious from simulated TKE profiles. Particles can arrive in such a non-turbulent environment by advective processes. From the TKE profiles, we can conclude, once again, that the CBL height is lower than the AL height. Even in sensitivity tests where sensible heat input from the surface was increased by decreasing the soil moisture content in the entire domain, the CBL height did not reach the AL height. De Wekker (2002) suggested the term 'mountain CBL' to denote the entire layer that is affected by heating from the valley surface, sidewalls, and mountain ridges on a timescale of one to several hours.

Because pollutants are transported and/or mixed in mountainous areas to the AL height, and this height is above the CBL height, the AL height is a more relevant parameter for air pollution studies and may be more closely identified with the commonly used term 'mixing height' (Seibert et al., 2000). If no information about the aerosol structure is available from aerosol lidar or other measurements, an LPDM simulation is a useful way to investigate the behaviour of the AL height, as demonstrated in this study. 


\section{Conclusions}

Observations from downlooking lidar on 1 day in the northern Alps in Europe show that aerosol-layer (AL) heights are rather uniform over the mountain range and increase from 2 to $3 \mathrm{~km}$ in the morning to over $4 \mathrm{~km}$ in the afternoon. AL top behaviour was modelled successfully using a coupled RAMS/HYPACT simulation in which particles were released from locations in two major valleys in the area. The simulation also compares well with aerosol surface area measurements at the Jungfraujoch research station.

CBL heights determined from model output show moderate terrain following behaviour, which contrasts with a rather uniform AL height. CBL heights become less terrain following in the afternoon in agreement with previous observations.

An important conclusion from this combined observational and numerical case study is that the CBL height is much lower than the AL height. CBL growth alone cannot explain the modelled particle distribution. Mechanisms were suggested to explain aerosol transport to regions above the CBL height in mountainous terrain. Mountain venting processes are thought to be responsible for the $\mathrm{AL} / \mathrm{CBL}$ height discrepancies, related to upvalley and usplope flows that dominate the wind field in the area. It is the organized vertical motion associated with these thermally driven flows that induces the mountain venting processes and the subsequent transport of particles above the CBL height. These processes are common over mountainous terrain and it is therefore suggested that the discrepancy between AL and CBL heights occurs more generally. The model results show that mountain venting processes are already efficient in the morning hours, implying that aerosols in higher layers during the morning hours are not necessarily remnants of residual layers, as is commonly believed.

In this case study performed in mountainous terrain, we have argued that the AL height, and not the CBL height, can be equated to the more commonly used term 'mixing height'. Whether this is generally the case in mountainous terrain requires further research. The current study showed that a mesoscale numerical model combined with an LPDM can provide useful estimates of AL heights if lidar data are not available.

\section{Acknowledgements}

One of the authors ( $\mathrm{SdW}$ ) wishes to thank the University of British Columbia (UBC) for a two-year University Graduate Fellowship, the Isaac Walton Killam Memorial Trust for a two-year pre-doctoral fellowship, and the UBC geography department for several teaching assistantships. Grants to DS from 
The Natural Sciences and Engineering Research Council of Canada also supported this research.

We also acknowledge funding from the EU-STAAARTE program and the German Aerospace Centre (DLR), Oberpfaffenhofen, for making the field study possible. André Prevôt is acknowledged for allowing SdW to finalize this paper while SdW held a post-doctoral appointment at the Paul Scherrer Institute. We would like to thank Drs. Chris Doran, André Prevôt, and Dave Whiteman for providing useful comments on the manuscript.

Support in the revision stage of this paper was received from the Department of Energy (DOE) under the auspices of the Atmospheric Sciences Program of the Environmental Sciences Division of the Office of Biological and Environmental Research under Contract DE-AC06-76RLO 1830 at the Pacific Northwest National Laboratory (PNNL). PNNL is operated for the US DOE by Battelle Memorial Institute.

\section{References}

Braham, R. R. and Draginis, M.: 1960, 'Roots of Orographic Cumuli', J. Meteorol. 17, 214 224.

Ching, J. K. S., Shipley, S. T., and Browell, E. V.: 1988, 'Evidence for Cloud Venting of Mixed Layer Ozone and Aerosols', Atmos. Environ. 22, 225-242.

Cotton, W. R., Pielke, Sr., R. A., Walko, R. L., Liston, G. E., Tremback, C. J., Jiang, H., McAnelly, R. L., Harrington, J. Y., Nicholls, M. E., Carrio, G. G., and McFadden, J. P.: 2003, 'RAMS 2001: Current Status and Future Directions', Meteorol. Atmos. Phys. 82, 529.

Coulter, R. L.: 1979, 'A Comparison of Three Methods for Measuring Mixing-Layer Height', J. Appl. Meteorol. 8, 1495-1499.

Cramer, O. P.: 1972, 'Potential Temperature Analysis for Mountainous Terrain', J. Appl. Meteorol. 11, 44-50.

Cramer, O. P. and Lynott, R. E.: 1961, 'Cross-section Analysis in the Study of Windflow over Mountainous Terrain', Bull. Am. Meteorol. Soc. 42, 693-702.

Dayan, U., Shenhav, R., and Graber, M.: 1988, 'The Spatial and Temporal Behavior of the Mixed Layer in Israel', J. Appl. Meteorol. 27, 1382-1394.

Deardorff, J. W., Willis, G. E., and Stockton, B. H.: 1980, 'Laboratory Studies of the Entrainment Zone of a Convectively Mixed Layer', J. Fluid Mech. 100, 41-64.

De Wekker, S. F. J.: 2002, Structure and Morphology of the Convective Boundary Layer in Mountainous Terrain, Ph.D. Dissertation, The University of British Columbia, BC, Canada, $191 \mathrm{pp}$.

De Wekker, S. F. J., Kossmann, M., and Fiedler, F.: 1997, 'Observations of Daytime Mixed Layer Heights over Mountainous Terrain during the TRACT Field Campaign', in Proceedings of the 12th AMS Symposium on Boundary Layers and Turbulence, Vancouver, BC, Canada, American Meteorological Society, 45 Beacon Street, Boston, MA, pp. 498-499.

Fast, J. D. and Zhong, S.: 1998, 'Meteorological Factors Associated with Inhomogeneous Ozone Concentrations within the Mexico City Basin', J. Geophys. Res. 103, 18927-18946.

Fiedler, F.: 1983, Einige Charakteristika der Strömung im Oberrheingraben, Wissenschaftliche Berichte des Meteorologischen Instituts der Universität Karlsruhe, Vol. 4, pp. 113-123. 
Fiedler, F., Bischoff-Gauss, I., Kalthoff, N., and Adrian, G.: 2000, 'Modeling of the Transport of a Tracer in the Freiburg-Schauinsland Area', J. Geophys. Res. D 105, 1599-1610.

Hänel, G.: 1976, 'The Properties of Atmospheric Aerosol Particles as Functions of the Relative Humidity at Thermodynamic Equilibrium with the Surrounding Moist Air', Adv. Geophys. 19, 73-188.

Holzworth, G. C.: 1964, 'Estimates of Mean Maximum Mixing Depths in the Contiguous U.S.', Mon. Wea. Rev. 92, 235-242.

Kiemle, C., Kästner, M., and Ehret, G.: 1995, 'The Convective Boundary Layer Structure from Lidar and Radiosonde Measurements during the EFEDA'91 Campaign', J. Atmos. Ocean. Tech. 12, 771-782.

Kossmann, M., Corsmeier, U., De Wekker, S. F. J., Fiedler, F., Vögtlin, R., Kalthoff, N., Güsten, H., and Neininger, B.: 1999, 'Observations of Handover Processes between the Atmospheric Boundary Layer and the Free Troposphere over Mountainous Terrain', Contr. Atmos. Phys. 72, 329-350.

Kossmann, M., Vögtlin, R., Corsmeier, U., Vogel, B., Fiedler, F., Binder, H.-J., Kalthoff, N., and Beyrich, F.: 1998, 'Aspects of the Convective Boundary Layer Structure over Complex Terrain', Atmos. Environ. 32, 1323-1348.

Lagouvardos, K., Kotroni, V., and Kallos, G.: 1996, 'Exploring the Effects of Different Types of Model Initialisation: Simulation of a Severe Air-Pollution Episode in Athens, Greece', Meteorol. Appl. 3, 147-155.

Lenschow, D. H., Stankov, B. B., and Mahrt, L.: 1979, 'The Rapid Morning Boundary-Layer Transition', J. Atmos. Sci. 36, 2108-2124.

Lu, R. and Turco, R. P.: 1994, 'Air Pollutant Transport in a Coastal Environment. Part 1: Two Dimensional Simulations of Sea-Breeze and Mountain Effects', J. Atmos. Sci. 51, 2285-2308.

Lugauer, M.: 1998, Vertical Transport of Atmospheric Trace Species in the Alps, Ph.D. Dissertation, University of Bern, Switzerland, $91 \mathrm{pp}$.

Lyons, W. A., Pielke, R. A., Cotton, W. R., Tremback, C. J., Walko, R. L., Uliasz, M., and Ibarra, J. I.: 1994, 'Recent Applications of the RAMS Meteorological and the HYPACT Dispersion Models', in S.-E. Gryning and M. M. Millan (eds.), Proceedings of the 20th ITM of NATO/CCMS on Air Pollution Modeling and its Application. Plenum Press, New York, pp. 19-26.

Marsik, F. J., Fischer, K. W., McDonald, T. D., and Samson, P. J.: 1995, 'Comparison of Methods for Estimating Mixing Height Used during the 1992 Atlanta Field Intensive', $J$. Appl. Meteorol. 34, 1802-1814.

McKendry, I. G. and Lundgren, J.: 2000, 'Tropospheric Layering of Ozone in Regions of Urbanized Complex and/or Coastal Terrain: A Review', Progr. Phys. Geog. 24, 329-354.

McKendry, I. G., Steyn, D. G., Lundgren, J., Hoff, R. M., Strapp, W., Anlauf, K., Froude, F., Martin, B. A., Banta, R. M., and Olivier, L. D.: 1997, 'Elevated Pollution Layers and Vertical Downmixing over the Lower Fraser Valley, B. C.', Atmos. Environ. 31, 2135-2146.

Nyeki, S., Kalberer, M., Colbeck, I., De Wekker, S. F. J., Furger, M., Gäggeler, H. W., Kossmann, M., Lugauer, M., Steyn, D., Weingartner, E., Wirth, M., and Baltensperger, U.: 2000, 'Convective Boundary Layer Evolution to $4 \mathrm{~km}$ asl over High-Alpine Terrain: Airborne Lidar Observations in the Alps', Geophys. Res. Lett. 27, 689-692.

Pielke, R. A.: 2002, Mesoscale Meteorological Modeling, 2nd edn., Academic Press, San Diego, CA, $676 \mathrm{pp}$

Raymond, D. and Wilkening, M.: 1980, 'Mountain Induced Convection under Fair Weather Conditions', J. Atmos. Sci. 37, 2693-2706. 
Schwiesow, R. L., 1984, 'Lidar Measurements of Boundary-Layer Variables', in D. H. Lenschow (ed.), Probing the Atmospheric Boundary Layer, Amer. Meteorol. Soc., pp. 139162.

Seibert, P., Beyrich, F., Gryning, S.E., Joffre, S., Rasmussen, A., and Tercier, P.: 2000, 'Review and Intercomparison of Operational Methods for the Determination of the Mixing Height', Atmos. Environ. 34, 1001-1027.

Sullivan, P. P., Moeng, C-H., Stevens, B., Lenschow, D. H., and Mayor, S. D.: 1998, 'Structure of the Entrainment Zone Capping the Convective Atmospheric BoundaryLayer', J. Atmos. Sci. 55, 3042-3064.

Troen, I. and Mahrt, L.: 1986, 'A Simple Model of the Atmospheric Boundary-Layer: Sensitivity to Surface Evaporation', Boundary-Layer Meteorol. 37, 129-148.

Van Pul, W. A. J., Holtslag, A. A. M., and Swart, D. P. J.: 1994, 'A Comparison of ABLheights Inferred Routinely from Lidar and Radiosondes at Noontime', Boundary-Layer Meteorol. 68, 173-191.

Vogelezang, D. H. P. and Holtslag, A. A. M.: 1996, 'Evaluation and Model Impacts of Alternative Boundary-Layer Height Formulations', Boundary-Layer Meteorol. 81, 245269.

Walko, R. L., Tremback, C. J., and Bell, M. J.: 2001, HYPACT. Hybrid Particle and Concentration Transport Model. User's Guide, $35 \mathrm{pp}$. [Available from ASTER Division, Mission Research Corporation, P. O. Box 466, Fort Collins, CO 80525-0466].

Whiteman, C. D.: 1990, 'Observations of Thermally Developed Wind Systems in Mountainous Terrain', in W. Blumen (ed.), Atmospheric Processes over Complex Terrain, Meteorol. Monogr., 23 (no. 45), Amer. Meteorol. Soc., Boston, MA, pp. 5-42.

WMO (World Meteorological Organization): 1993, Handbook of Meteorological Forecasting for Soaring Flights, 2nd edn., Technical Note No. 158, WMO No. 495, Geneva, Switzerland, $84 \mathrm{pp}$. 